\title{
Kendiliğinden Yerleşen Betonlarda Çimento ile Yüksek Fırın Cürufunun Yüksek Oranlarda Yer Değiştirmesinin Betonun Fiziksel ve Mekanik Özelliklerine Etkisi
}

\author{
* Ayşe MOLLAİSMAIILOĞLU \\ Kocaeli Üniversitesi, Fen Bilimleri Enstitüsü \\ Onur ÖZTÜRK \\ Kocaeli Üniversitesi, Mühendislik Fakültesi \\ Adnan ÖNER \\ Kocaeli Üniversitesi, Mühendislik Fakültesi \\ Kocaeli / Türkiye \\ 2019
}

\begin{abstract}
Özet
Bu çalışmanın amacı çimento ile yüksek oranlarda yüksek firın cürufunu (YFC) yer değiştirerek kendiliğinden yerleşen beton (KYB) elde etmek ve bu betonların mekanik özelliklerini incelemektir. Hazırladığımız karışımlarda çimento ile yüksek firın cürufu $\% 15, \% 30, \% 45, \% 60, \% 75$ ve $\% 90$ oranlarında yer değiştirilmiştir. Bunlara ek cüruf kullanılmadan elde edilen referans numunesiyle birlikte 7 farklı karışım elde edilmiştir. KYB 'lerde hiper akışkanlaştırıı katkı (HA), doğal kum, kırma kum ve kırma taş kullanılmıştır. Elde edilen betonda taze beton deneyi olarak yayılma deneyi (slump deneyi) yapılmıştır. Ardından silindir, prizma ve aşınma deneyi için küp kalıplara beton dökülerek numuneler elde edilmiştir. Numuneler üzerinde 7 ve 28 günlük basınç, yarmada çekme, eğilme ve 28 günlük aşınma deneyleri yapılmıştır. Kontrol numunesi referans alınarak çıkan sonuçlar değerlendirilmiştir. Sonuçlara göre YFC ile çimento yer değiştirme oranının \%45'e kadar olumlu sonuç verdiği, $\% 45$ 'ten fazla yer değiştirme yapıldığında ise taşıma değerleri düşerken aşınma direncinin yeterli sonuçlar verdiği görülmüştür.
\end{abstract}

Anahtar Kelimeler: Kendiliğinden yerleşen beton, yüksek firın cürufu, çimento

\begin{abstract}
The aim of this study is to replace the cement and high blast furnace slag (GGBS) to obtain selfcompacting concrete (SCC) and to investigate the mechanical properties of these concretes. Cement and blast furnace slag were replaced by $15 \%, 30 \%, 45 \%, 60 \%, 75 \%$ and $90 \%$ in the mixtures we prepared. 7 different mixtures were obtained with the reference sample obtained without using additional slag. Hyper plasticizing additive (HP), natural sand, crushed sand and crushed stone were used in mixtures. In the obtained concrete, spreading test (slump test) was performed as fresh concrete test. Then, concrete was poured into cube molds for cylinder, prism and abrasion test and samples were obtained. Samples were subjected to 7 and 28 days of pressure, tensile, bending and 28 days of abrasion tests. The results were evaluated with reference to the control sample. According to the results, it is seen that the cement displacement rate with YFC is positive up to $45 \%$, and when the displacement is more than $45 \%$, abrasion resistance decreases while carrying values decrease.
\end{abstract}

Key Words: Self compacting concrete, blast furnace slag, cement

\section{GİRIŞ}


Kendiliğinden yerleşen beton ile ilgili çalışmalar ilk olarak 1986 yılında Japonya'da Tokyo Üniversitesi'nde yapılmıştır. Su altı yapılarında beton dökümü üzerine yapılan çalışmalar sonucu bulunmuştur.[1-2]

KYB'ler hiçbir sıkışma işlemi gerekmeksizin kendi ağırlığıyla kalıbı dolduran, en dar ve ulaşılması güç yerlere bile vibratörsüz ulaşabilen, ayrışmaya karşı dirençli, geçirimliliği düşük ve yalıtım değerleri diğer betonlara yüksek olan özel bir beton türüdür[3].

KYB'ler bütün imalat alanlarında rahatlıkla kullanılabilir. Akışkanlığının yanı sıra imalat süresini kısaltma, işçilik maliyetini düşürme, özellikle sık donatılı betonarme elemanlarda betonun kalıba boşluksuz bir şekilde yerleşmesini sağlama ve vibrasyondan kaynaklanan ses kirliliğini azaltma gibi geleneksel betona göre birçok üstünlüğ̈̈ bulunmaktadır[4]. Ayrıca KYB'ler betonarme yapıların onarım ve güçlendirilmesinde ve prefabrik yapıların üretiminde de önemli rol almaktadır.

Ancak KYB'nin üretim maliyeti diğer betonlara göre yüksektir. KYB üretiminde diğer betonlara göre çimento ve ince agrega kullanımı daha fazla iken iri agrega kullanımı daha azdır. Yani açıkçası KYB'yi diğerlerinden ayıran faktör iyi bir agrega granülometrisidir. KYB tasarımını etkileyen bir diğer faktör ise akışkanlaştırıcı katkı kullanımıdır.[5-7]

Öte yandan çevresel kirliliğin önüne geçmek adına atık geri dönüşüm uygulamaları ülkemizde yaygın olarak devam etmektedir. Bu atıklardan biri olan, YFC demir üretimi esnasında açığa çıkan bir yan üründür. Demir-çelik tesislerindeki firınlarda sıcaklıklar 1600 oC 'a ulaşmaktadır. Bu sıcaklıkta YFC hammaddenin üst kısmında toz şeklinde ayrışır. Ve fırından ayrı ayrı tahliye edilirler[8]. Ardından kullanım alanına göre YFC aniden soğutularak granüle hale getirilir ve daha sonrasında ögütülür. Öğütülen bu malzeme beton üretiminde kullanılabilmektedir. YFC'nin taze ve sert betonun fiziksel ve mekanik özelliklerine birçok olumlu etkisi bulunduğu bilinmektedir[9].Bunlardan başlıcaları betonun priz süresini uzatması, su ihtiyacını azaltması, hava boşluğunu azaltması, termal çatlaklar, sünme-rötre ve korozyonu azaltması olarak sayılabilir.

Yaprak ve diğ. yaptıkları çalışmada YFC 'yi ağırlıkça \% 0, \% 10, \% 20 ve \% 30 oranlarında çimento ile ikame ettirmiş ve numuneler hazırlamış, bu numuneler üzerinde çökme, basınç ve yarmada çekme deneyleri uygulamışlardır. Bu çalışma sonucunda YFC miktarı arttıkça beton karışımlarının işlenebilirliğinin azaldığını ve betonda YFC ikame oranı yükseldikçe bütün yaşlarda basınç dayanımlarının \% 20'ye kadar arttığını \% 30 ikame oranında azaldığını belirtmişlerdir[10].

Kalkan ve diğ. KYB karışımlarında 50, 100, 150, 200 ve $250 \mathrm{~kg}$ miktarında YFC ile çimento ikame ettirmişlerdir. Kontrol betonuyla birlikte 6 ayrı karışım elde etmişlerdir. HA ve s/b oranını sabit tuttukları numunelerde yayılma, basınç ve yarmada çekme deneyleri uygulamışlardır. YFC ikameli betonların çökme-yayılma değerlerinin kontrol betonuna göre daha fazla olduğu görülmüştür. 7 günlük basınç dayanım değerlerinin YFC ikame miktarı arttıkça azaldığı ve en yüksek basınç değerinin en az YFC ikamesine sahip olan numunenin olduğu belirlenmiştir. 28 günlük sonuçlarda ise KYB içerisine konulan YFC'nin basınç dayanımını artırdığı gözlemlemişlerdir.[11]

\section{AMAÇ}


Bu çalışmada YFC 'nin KYB üzerindeki fiziksel, mekanik ve aşınma etkileri araştırılmıştır. Elde edilen deney sonuçları göz önünde bulundurularak YFC içeren betonların basınç, eğilme ve yarma dayanımları ile aşınmaya karşı gösterdikleri direnç yorumlanmıştır. YFC 'nin dayanım değerleri üzerindeki etkileri kontrol betonuyla karşılaştırılmıştır. Bu değerlendirmeler yardımıyla, kullanılabilecek maximum YFC yüzdesinin belirlenmesi ve uygun kullanım alanlarının değerlendirilmesi amaçlanmıştır.

\section{MATERYAL}

\subsection{Agrega}

Bu çalışmada; ince agrega olarak doğal kum ve kırma kum, iri agrega olarak ise kırma taş kullanılmıştır.

Tablo 1. Kullanılan agregaların granülometrik bileşimleri

\begin{tabular}{cccc}
\hline \multicolumn{3}{c}{ Elek Analizi Sonuçları } \\
\hline $\begin{array}{c}\text { Elek } \\
\text { Boyutu } \\
(\mathbf{m m})\end{array}$ & $\begin{array}{c}\text { Doğal } \\
\text { Kum }\end{array}$ & Kirmataş & Kırmakum \\
\hline 16 & 100 & 100 & 100 \\
\hline 8 & 100 & 75 & 100 \\
\hline 4 & 100 & 33 & 96 \\
\hline 2 & 70 & 2 & 68 \\
\hline 1 & 50 & 1 & 40 \\
\hline 0,5 & 34 & 1 & 16 \\
\hline 0,25 & 19 & 1 & 2,55 \\
\hline $\begin{array}{c}\text { İncelik } \\
\text { Modülü }\end{array}$ & 2,28 & 4,88 & \\
\hline
\end{tabular}

TS EN 932-1 standardı esas alınarak hazırlanan doğal kum, kırma kum ve kırma taş bileşiminin granülometrik dağılımını bulabilmek için numuneler üzerinde 2,25 - $16 \mathrm{~mm}$ elek takımı kullanılmıştır[13]. Elek analizi TS EN 933-1 standardına uygun olarak yapılmıştır[14]. 


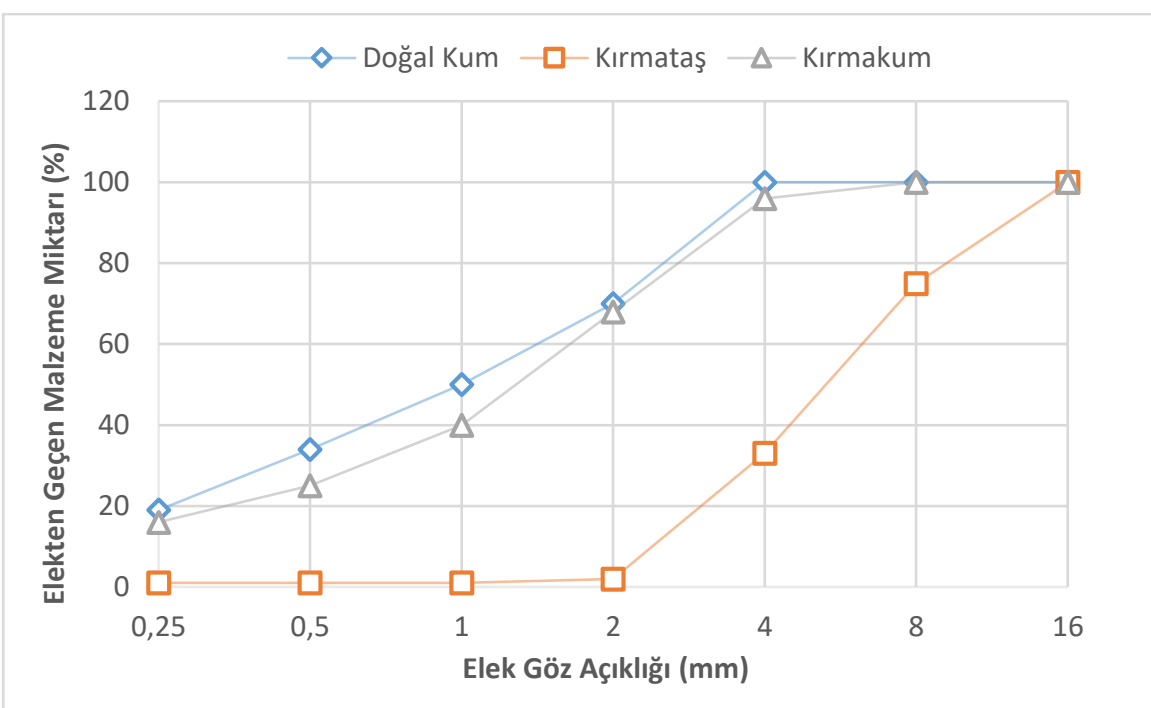

Şekil 1. KYB üretiminde kullanılan agregaların granülometrik dağılımı

\section{2 Çimento}

Beton numunelerin üretiminde kullandığımız çimento CEM 1 42,5 R (PÇ 42,5) çimentosu olup, Akçansa Çimento Sanayi ve Ticaret A.Ş.'den temin edilmiştir.

Tablo 2. Kullanılan çimentonun mekanik özellikleri

\section{Mekanik Özellikler}

\begin{tabular}{cc}
\hline Basınç Dayanımları $(\mathrm{MPa})$ & $(40 x 40 \times 160 \mathrm{~mm}$ küp numuneler için $)$ \\
\hline 2 Günlük & 38,6 \\
\hline 7 Günlük & 47,0 \\
\hline 28 Günlük & 57,4 \\
\hline
\end{tabular}

Tablo 3. Kullanılan çimentonun kimyasal bileşimi

\begin{tabular}{|c|c|}
\hline \multicolumn{2}{|c|}{ Kimyasal Özellikler } \\
\hline İncelenen Maddeler & Elde Edilen Değerler (\%) \\
\hline $\mathrm{SiO}_{2}$ & 19,41 \\
\hline $\mathrm{Al}_{2} \mathrm{O}_{3}$ & 4,50 \\
\hline $\mathrm{Fe}_{2} \mathrm{O}_{3}$ & 3,49 \\
\hline $\mathrm{CaO}$ & 63,09 \\
\hline $\mathrm{MgO}$ & 2,51 \\
\hline $\mathrm{SO}_{3}$ & 3,05 \\
\hline Çözünmeyen Kalıntı & 0,30 \\
\hline Kızdırma Kayb1 & 2,39 \\
\hline Serbest Kireç & 1,42 \\
\hline
\end{tabular}


A. Mollaismailoğlu ve diğ./ISITES2019 ŞanlıUrfa - Türkiye

Tablo 4. Kullanılan çimentonun fiziksel özellikleri

Fiziksel Özellikler

\begin{tabular}{lc}
\hline \multicolumn{1}{c}{ İncelenen Özellikler } & Elde Edilen Değerler \\
\hline Priz Başlangıcı (dakika) & 150 \\
\hline Priz Sonu (dakika) & 205 \\
\hline Hacim Sabitliği $(\mathrm{mm})$ & 1,00 \\
\hline Özgül Yüzey $\left(\mathrm{cm}^{2} / \mathrm{gr}\right)$ & 3814 \\
\hline Özgül Ağırlık $\left(\mathrm{gr} / \mathrm{cm}^{3}\right)$ & 3,12 \\
\hline
\end{tabular}

\subsection{Yüksek Firın Cürufu}

Bu çalışmada kullanılan YFC, TS EN 15167-1 standardına uygun olarak, Nuh Çimento Sanayi ve Ticaret A.Ş. den temin edilmiştir[15]. Kimyasal ve fiziksel analizleri Tablo 3 ve Tablo 4 te verilmiştir.

Tablo 5. Yüksek firın cürufu kimyasal bileşimi

\begin{tabular}{lcc}
\hline Kimyasal Analiz Sonuçları & $\%$ & Standart \\
\hline $\mathrm{SiO} 2$ & 37,29 & \\
$\mathrm{~A} 12 \mathrm{O} 3$ & 11,76 & \\
$\mathrm{Fe} 2 \mathrm{O} 3$ & 1,77 & \\
\hline $\mathrm{CaO}$ & 33,09 & \\
$\mathrm{MgO}$ & 7,12 & maks. 18 \\
\hline $\mathrm{SO} 3$ & 1,51 & maks.2,5 \\
\hline $\mathrm{K} 2 \mathrm{O}$ & 1 & \\
\hline $\mathrm{Na} 2 \mathrm{O}$ & 0,15 & \\
\hline $\mathrm{T}$ oplam Alkali & 0,81 & \\
Na2O+0,658 K2O & & \\
\hline K1zdırma Kayb1 & 0,25 & maks.3 \\
\hline Klorür & 0,0075 & maks.0,1 \\
\hline Sülfür (S-2) & 0,1 & maks.2,5 \\
\hline
\end{tabular}

Tablo 6. Yüksek firın cürufu fiziksel özellikleri

\begin{tabular}{lcc}
\hline Fiziksel Analiz Sonuçları & & \\
\hline Nem Muhtevası (\%) & 0,38 & maks.1 \\
\hline Özgül Ağırlık (g/cm3) & 2,92 & \\
\hline Özgül Yüzey (Blaine, cm2/g) & 4537 & min.2750 \\
\hline 32 mm elek bakiye (\%) & 2,1 & \\
\hline 45 mm elek bakiye (\%) & 0,1 & \\
\hline 90 mm elek bakiye (\%) & 0 & \\
\hline
\end{tabular}




\subsection{Hiper Akışkanlaştırıcı Katkı}

Hazırladığımız beton numunelerinin karışımında KYB özelliğini kazanması için hiper akışkanlaştırıcı katkı kullanılmıştır. Chryso Yapı Kimyasalları'nın ürünü olan Chryso Delta 489 W katkısı temin edilmiştir. Özellikleri Tablo 5 te verilmiştir.

Tablo 7. Kullanılan hiper akışkanlaştırıcı katkı özellikleri

\begin{tabular}{cccccc}
\hline Katkı Adı & Görünüm & Renk & Yoğunluk(gr/cm3) & pH & Klorür İçeriği \\
\hline CHRYSO ${ }^{2}$ Delta $489 \mathrm{~W}$ & \multirow{2}{*}{ Siv1 } & Kahverengi & $1,07 \pm 0,02$ & $8,0 \pm 1$ & $<\% 0,1$ \\
\hline
\end{tabular}

\section{METOT}

Beton üretiminde TS 802 de yer alan karışım hesapları esas alınmıştır[16]. C45 beton sınıfına sahip olarak hazırladığımız karışımlarda doğal kum, kırma kum, kırma taş olmak üzere 3 farklı sınıfta agrega kullanılmıştır. Karışımlarda s/b oranı ve HA oranı sabit tutulmuştur. HA, karışıma su ile çözelti oluşturduktan sonra dahil edilmiştir. YFC, çimento ile ağırlıç̧a \%15, $\% 30, \% 45, \% 60, \% 75, \% 90$ gibi yüksek oranlarda ikame edilerek, kontrol betonu ile birlikte 7 ayrı karışım elde edilmiştir. Üretilen beton karışımlarının $1 \mathrm{~m}^{3}$ için kullanılan miktarları aşağıda tabloda belirtilmiştir.

Tablo 8. Yüksek Oranda YFC ile üretilen KYB karışımının $1 \mathrm{~m}^{3}$ için malzeme miktarları

\begin{tabular}{|c|c|c|c|c|c|c|c|c|}
\hline & $\begin{array}{l}\text { Özgül } \\
\text { Ăglrlık } \\
\left(\mathbf{g} / \mathrm{cm}^{3}\right)\end{array}$ & КYBO0 & KYB15 & KYB30 & KYB45 & КYB60 & KYB75 & KYB90 \\
\hline Çimento $\left(\mathrm{kg} / \mathrm{m}^{3}\right)$ & 3,16 & 450 & 382,5 & 315 & 247,5 & 180 & 112,5 & 45 \\
\hline YFC (\%) & & 0 & 15 & 30 & 45 & 60 & 75 & 90 \\
\hline YFC $\left(\mathrm{kg} / \mathrm{m}^{3}\right)$ & 2,75 & 0 & 67,5 & 135 & 202,5 & 270 & 337,5 & 405 \\
\hline $\mathrm{Su}\left(\mathrm{kg} / \mathrm{m}^{3}\right)$ & 1,00 & 193,5 & 193,5 & 193,5 & 193,5 & 193,5 & 193,5 & 193,5 \\
\hline Su/Çimento & & 0,43 & 0,43 & 0,43 & 0,43 & 0,43 & 0,43 & 0,43 \\
\hline İnce Agrega 1 - Kırmakum $\left(\mathrm{kg} / \mathrm{m}^{3}\right)$ & 2,66 & 650 & 650 & 650 & 650 & 650 & 650 & 650 \\
\hline İnce Agrega 2 - Doğal Kum $\left(\mathrm{kg} / \mathrm{m}^{3}\right)$ & 2,66 & 450 & 450 & 450 & 450 & 450 & 450 & 450 \\
\hline İri Agrega $\left(\mathrm{kg} / \mathrm{m}^{3}\right)$ & 2,69 & 580 & 580 & 580 & 580 & 580 & 580 & 580 \\
\hline Hiper Akışkanlaştırıcı (\%) & & 1,5 & 1,5 & 1,5 & 1,5 & 1,5 & 1,5 & 1,5 \\
\hline Hiper Akışkanlaştırıcı $\left(\mathrm{kg} / \mathrm{m}^{3}\right)$ & 1,23 & 6,75 & 6,75 & 6,75 & 6,75 & 6,75 & 6,75 & 6,75 \\
\hline Hava $(\%)$ & & 1,80 & 1,80 & 1,80 & 1,80 & 1,80 & 1,80 & 1,80 \\
\hline
\end{tabular}

Beton yukarıdan karıştırma özelliği olan, $65 \mathrm{dm} 3$ kapasiteli mikserde, sabit süreler ile karıştırılmıştır. Üretilen betonlar 100mmx400mm'lik prizma, 100mmx200mm'lik silindir, $71 \mathrm{mmx} 71 \mathrm{~mm}$ 'lik küp kalıplara dökülmüştür. Ardından numuneler $20 \pm 2{ }^{\circ} \mathrm{C}$ ve $\% 40-60$ bağ 1 neme sahip olan laboratuvar koşullarında, nemli bezle kür edilerek 3 gün boyunca bekletilmiş, daha sonra kalıplardan çıkarılmıştır. Kalıplardan çıkarılan numuneler kür havuzlarında bekletilmiştir. Numuneler üzerinde 7 ve 28 günlük basınç, yarmada çekme, eğilme ve 28 günlük 
aşınma deneyleri yapılmıştır. Basınç, yarmada çekme ve eğilme deneyleri Baz Makina Marka $3000 \mathrm{kN}$ kapasiteli deney aleti ile yapılmıştır. Aşınma (Böhme) deneyi ise $30( \pm 1)$ devir/dk hızla dönen $750 \mathrm{~mm}$ çaplı yatay aşındırma diski, kaldıraç kolu, numune yükleme ağırlığı, karşı ağırlık ve numune tutucu aparattan oluşan cihazda yapılmıştır. TS2824 e göre hazırladığımız kenar uzunlukları $71 \mathrm{~mm} \pm 1,5 \mathrm{~mm}$ olan numunelerin birbirini takip eden 4 yüzeyi aşınmaya tabi

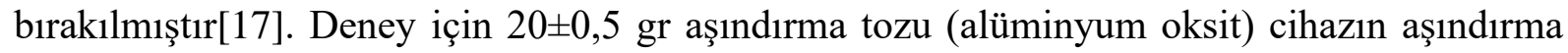
yüzeyine serpilir ve numunenin üst yüzeyi numune tutucu aparatın yan yüzeyine gelecek şekilde yerleştirilir. Birbirini takip eden 4 yüzey aşınmaya tabi tutulur. Bu 4 yüzeyin her biri için otomatik sayaçlı olan cihaz 22 devir yapar. $\mathrm{Bu} 4$ tur sonunda aşındırma tozu makine yüzeyinden temizlenir ve yeni aşındırma tozu serpilir. Numune tartılır, aynı işlem 4 defa tekrarlanır. Toplam 16 defa numuneye aşındırma işlemi uygulanır. Numunelerin yüzeylerinde meydana gelen kısalma ve ağırlıkça azalma ölçülür ve hacim hesabı yapılır. Numunenin tabanı $50 \mathrm{~cm}^{2}(71 \mathrm{~mm} \times 71 \mathrm{~mm})$ olduğundan tüm değerlendirmeler bu taban alanı esas alınarak yapılmıştır. Aşınma deneyi TS 699 standardına göre yapılmıştır[18].

\section{DENEY SONUÇLARI}

\subsection{Taze Beton Değerleri}

Bir betonun KYB olarak değerlendirilmesi için Abrams Konisinde deney yapılarak elde edilen yayılmasının 550 ile $850 \mathrm{~mm}$ arasında olması gerektiği bilinmektedir[1]. EFNARC'a (European Federation of National Trade Associations) göre bu yayılma değeri 3 ayrı sinıfta değerlendirilmiştir. 1.sınıf (SF1) 550 ile 650mm, 2. Sınıf (SF2) 660 ile 750mm, 3. Sınıf (SF3) 760 ile $850 \mathrm{~mm}$ arasında olmalıdır. Yayılma çapının $50 \mathrm{~cm}$ genişliğe erişme süresi (T50) ve huniden çıkış süresi ise 2 ayrı sınıfta değerlendirilmiştir. 1.sınıf (VS1) in T50 süresi 2 s'den az, huniden çıkış1 $8 \mathrm{~s}$ den az ve 2.sınıf (VS2) için T50 süresi 2s den fazla, huniden çıkış süresi 925s arasinda olmalidir[12].

Tablo 9. EFNARC’a göre yayılma değerleri

\begin{tabular}{cc}
\hline Sinıf & Slump Değeri(mm) \\
\hline SF1 & $550-650$ \\
\hline SF2 & $660-750$ \\
\hline SF3 & $760-850$ \\
\hline
\end{tabular}

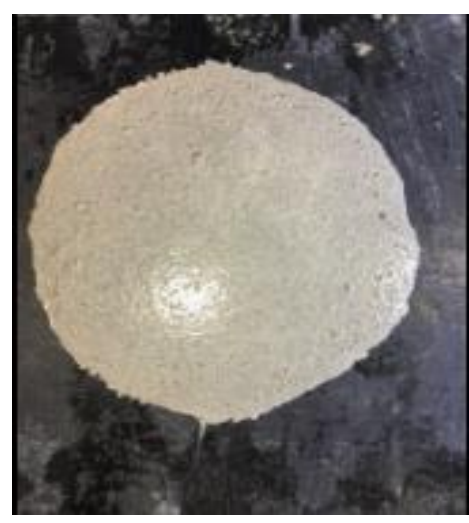

Şekil 2. Yayılma Deneyi Numunesi

Yayılma deney sonucunu tayin etmek için yayılan beton 3 ayrı noktadan ölçülüp ortalaması alınmıştır. Hesaplanan yayılma çapları, birim ağırlık değerleri ve hava oranları Tablo 10 'da verilmiştir.

Tablo 10. YFC ile üretilen KYB'lerin taze beton deney sonuçları 
A. Mollaismailoğlu ve diğ./ISITES2019 ŞanlıUrfa - Türkiye

\begin{tabular}{|c|c|c|c|c|c|}
\hline $\begin{array}{l}\text { Beton } \\
\text { Kodu }\end{array}$ & $\begin{array}{c}\text { Çimento } \\
(\mathbf{k g})\end{array}$ & $\begin{array}{l}\text { YFC } \\
(\mathrm{kg})\end{array}$ & $\begin{array}{c}\text { Çökme-Yayılma } \\
\text { (mm) } \\
\text { T50s }\end{array}$ & $\begin{array}{c}\text { Birim } \\
\text { Ağırlık } \\
(\mathbf{k g} / \mathbf{m 3})\end{array}$ & $\begin{array}{c}\text { Hava } \\
\%\end{array}$ \\
\hline \multirow{2}{*}{ КУВОО } & \multirow{2}{*}{450} & \multirow{2}{*}{0} & $\mathrm{Y}=686$ & \multirow{2}{*}{2,403} & \multirow{2}{*}{4,8} \\
\hline & & & $\mathrm{t}=5$ & & \\
\hline \multirow{2}{*}{ KYB15 } & \multirow{2}{*}{382,5} & \multirow{2}{*}{67,50} & $\mathrm{Y}=704$ & \multirow{2}{*}{2,390} & \multirow{2}{*}{3,2} \\
\hline & & & $\mathrm{t}=6$ & & \\
\hline \multirow{2}{*}{ КYВ3О } & \multirow{2}{*}{315} & \multirow{2}{*}{135} & $\mathrm{Y}=712$ & \multirow{2}{*}{2,375} & \multirow{2}{*}{2,1} \\
\hline & & & $\mathrm{t}=7$ & & \\
\hline \multirow{2}{*}{ KYB45 } & \multirow{2}{*}{247,5} & \multirow{2}{*}{202,5} & $\mathrm{Y}=734$ & \multirow{2}{*}{2,356} & \multirow{2}{*}{2,3} \\
\hline & & & $\mathrm{t}=9$ & & \\
\hline \multirow{2}{*}{ КYВ60 } & \multirow{2}{*}{180} & \multirow{2}{*}{270} & $\mathrm{Y}=693$ & \multirow{2}{*}{2,337} & \multirow{2}{*}{2,2} \\
\hline & & & $\mathrm{t}=10$ & & \\
\hline \multirow{2}{*}{ KYB75 } & \multirow{2}{*}{112,5} & \multirow{2}{*}{337,5} & $Y=727$ & \multirow{2}{*}{2,319} & \multirow{2}{*}{1,2} \\
\hline & & & $\mathrm{t}=11$ & & \\
\hline \multirow{2}{*}{ КYB90 } & \multirow{2}{*}{45} & \multirow{2}{*}{405} & $\mathrm{Y}=746$ & \multirow{2}{*}{2,298} & \multirow{2}{*}{1,0} \\
\hline & & & $\mathrm{t}=12$ & & \\
\hline
\end{tabular}

Yayılma değerlerinin EFNARC'a (European Federation of National Trade Associations) göre SF2 sınıfını sağladığ1 Tablo 10 'da görülmektedir. En fazla yayılma değeri KYB90 numunesinde, en düşük yayılma değeri ise kontrol betonunda elde edilmiştir. T50 sürelerinin YFC ikamesi arttıkça uzadığg görülmektedir.

Yapılan hesaplara göre numunelerin YFC ikamesi arttıkça birim ağırlıklarının azaldığı görülmüştür. Tablo 10' a göre YFC ikamesi olmayan kontrol betonu ise en yüksek hava yüzdesine sahiptir.

\subsection{SERT BETON DENEYLERI}

\subsubsection{Basınç Dayanımı}

C45 olarak tasarımı yapılan beton numunelerinin 7 ve 28 günlük basınç dayanım değerleri Tablo 11'de verilmiştir.

Tablo 11. YFC ile üretilen sertleşmiş betonların 7 ve 28 günlük basınç dayanım değerleri

\begin{tabular}{|c|c|c|}
\hline \multirow{2}{*}{$\begin{array}{c}\text { Beton } \\
\text { Kodu }\end{array}$} & \multicolumn{2}{|c|}{ Basınç Dayanımı (Mpa) } \\
\cline { 2 - 3 } KYB00 & $\mathbf{7}$ gün & 28 gün \\
\hline KYB15 & 44,15 & 45,08 \\
\hline KYB30 & 40,27 & 45,36 \\
\hline KYB45 & 35,34 & 39,78 \\
\hline KYB60 & 29,06 & 39,58 \\
\hline KYB75 & 18,72 & 28,89 \\
\hline KYB90 & 5,87 & 21,95 \\
\hline \multicolumn{2}{|c|}{} \\
\hline
\end{tabular}


Tablo 11' de görüldüğü gibi 7 günlük en yüksek basınç dayanımına sahip olan değer, 44,15 Mpa ile kontrol numunesine aittir. 28 günlük numunelerde ise en yüksek basınç dayanımı en az YFC ikamesine sahip olan KYB15 numunesindedir. YFC ikamesi en fazla olan KYB90 numunesi ise 7 ve 28 günlük için en düşük dayanıma sahiptir.

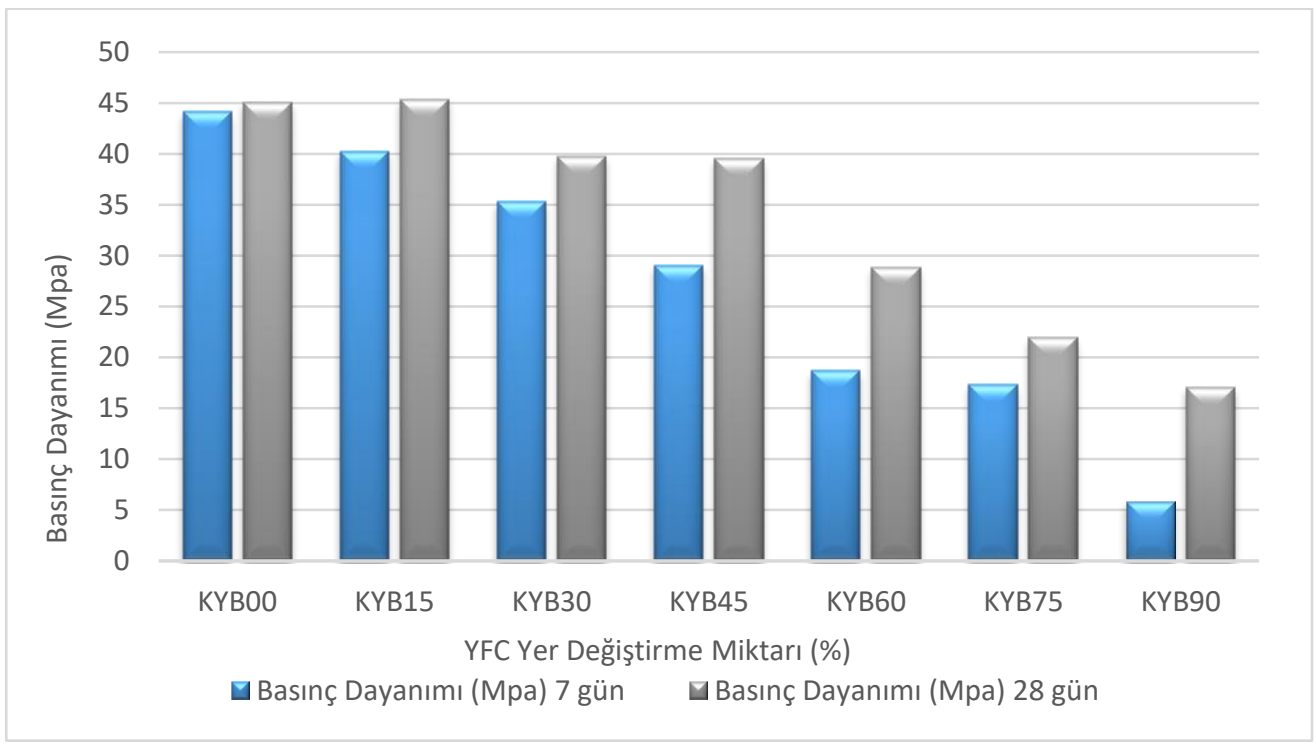

Şekil 3. YFC ile üretilen sertleşmiş betonların 7 ve 28 günlük basınç dayanımlarının ilişkisi

Şekil 3 'teki grafikte 7 ve 28 günlük basınç dayanımlarının arasındaki ilişki verilmiştir. YFC ikamesi olmayan KYB00 numunesinde 28 günlük basınç değeri az miktarda artarken YFC ikamesi olan numunelerde basınç dayanım değerlerinin daha fazla arttığı görülmektedir.

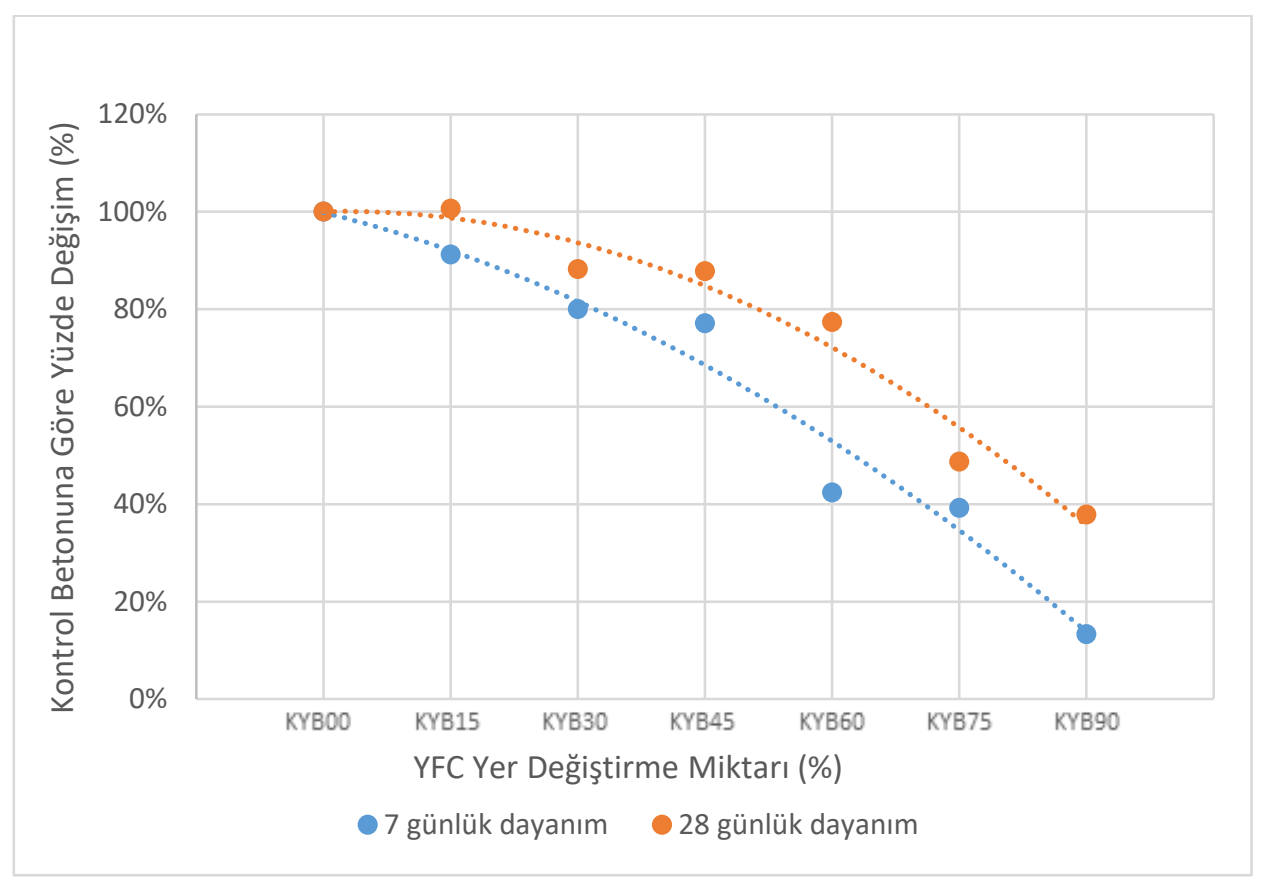

Şekil 4. YFC ile üretilen betonların 7 ve 28 günlük basınç dayanımlarının \% değişim ilişkisi 


\subsubsection{Yarmada Çekme Dayanımı}

100mmx200mm'lik silindir kalıplara konularak kür edilen numunelerin 7 ve 28 günlük yarmada çekme dayanım değerleri Tablo 12 'de verilmiştir.

Tablo 12. YFC ile üretilen sertleşmiş betonların 28 günlük yarmada çekme dayanım değerleri

\begin{tabular}{|c|c|c|}
\hline \multirow{2}{*}{$\begin{array}{c}\text { Beton } \\
\text { Kodu }\end{array}$} & \multicolumn{2}{|c|}{ Çekme Dayanımı (Mpa) } \\
\cline { 2 - 3 } & $\mathbf{7}$ gün & 28 gün \\
\hline$K Y B 00$ & 3,51 & 3,90 \\
\hline$K Y B 15$ & 2,98 & 3,14 \\
\hline$K Y B 30$ & 2,35 & 3,05 \\
\hline$K Y B 45$ & 2,70 & 3,15 \\
\hline$K Y B 60$ & 1,80 & 2,73 \\
\hline$K Y B 75$ & 2,25 & 3,14 \\
\hline$K Y B 90$ & 1,40 & 2,61 \\
\hline
\end{tabular}

Tablo 12 'de görüldüğü gibi 7 günlük ve 28 günlük en yüksek yarmada çekme dayanımına sahip olan numune YFC ikamesi bulunmayan KYB00 numunesidir.

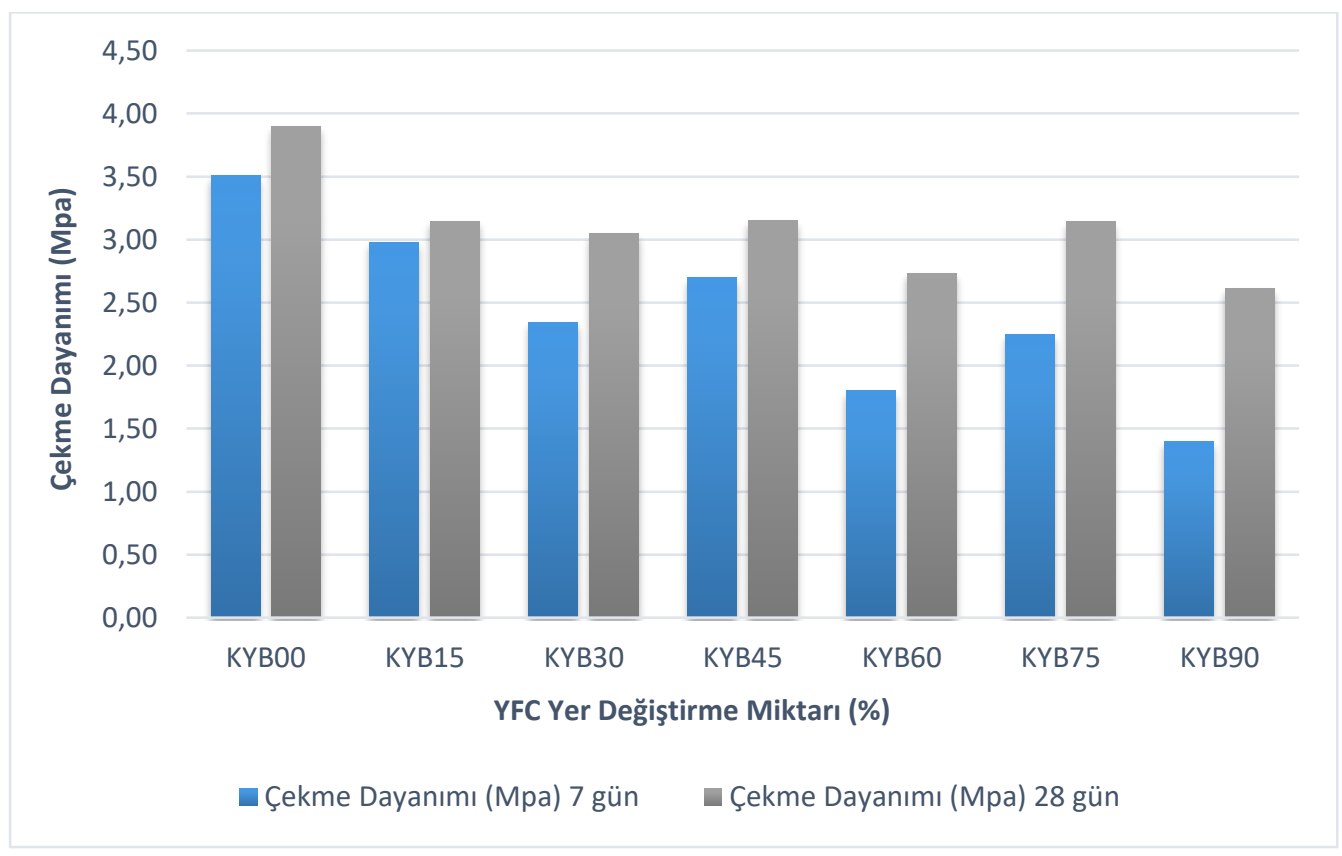

Şekil 5. YFC ile üretilen sertleşmiş betonların 7 ve 28 günlük yarmada çekme dayanımlarının ilişkisi

\subsection{3 Ĕ̈ilme Deneyi}

100mmx400mm'lik prizma kalıplara dökülerek yaşını alana kadar kür edilen numunelerin eğilme dayanım değerleri Tablo 13 'te verilmiştir. 
A. Mollaismailoğlu ve diğ./ISITES2019 ŞanlıUrfa - Türkiye

Tablo 13. YFC ile üretilen sertleşmiş betonların 28 günlük yarmada çekme dayanım değerleri

\begin{tabular}{|c|c|c|}
\hline \multirow{2}{*}{$\begin{array}{l}\text { Beton } \\
\text { Kodu }\end{array}$} & \multicolumn{2}{|c|}{ Eüilme Dayanımı (Mpa) } \\
\cline { 2 - 3 } & $\mathbf{7}$ gün & $\mathbf{2 8}$ gün \\
\hline$K Y B 00$ & 4,709 & 5,967 \\
\hline$K Y B 15$ & 4,827 & 5,165 \\
\hline$K Y B 30$ & 3,892 & 4,334 \\
\hline$K Y B 45$ & 4,694 & 5,628 \\
\hline$K Y B 60$ & 2,921 & 4,179 \\
\hline$K Y B 75$ & 2,708 & 3,613 \\
\hline$K Y B 90$ & 1,398 & 3,333 \\
\hline
\end{tabular}

Tablo 13 'te görüldüğü gibi 7 günlük en yüksek dayanım en düşük YFC miktarına sahip olan KYB15 numunesindedir. 28 günlük en yüksek dayanım ise YFC ikamesi bulunmayan kontrol numunesindedir.

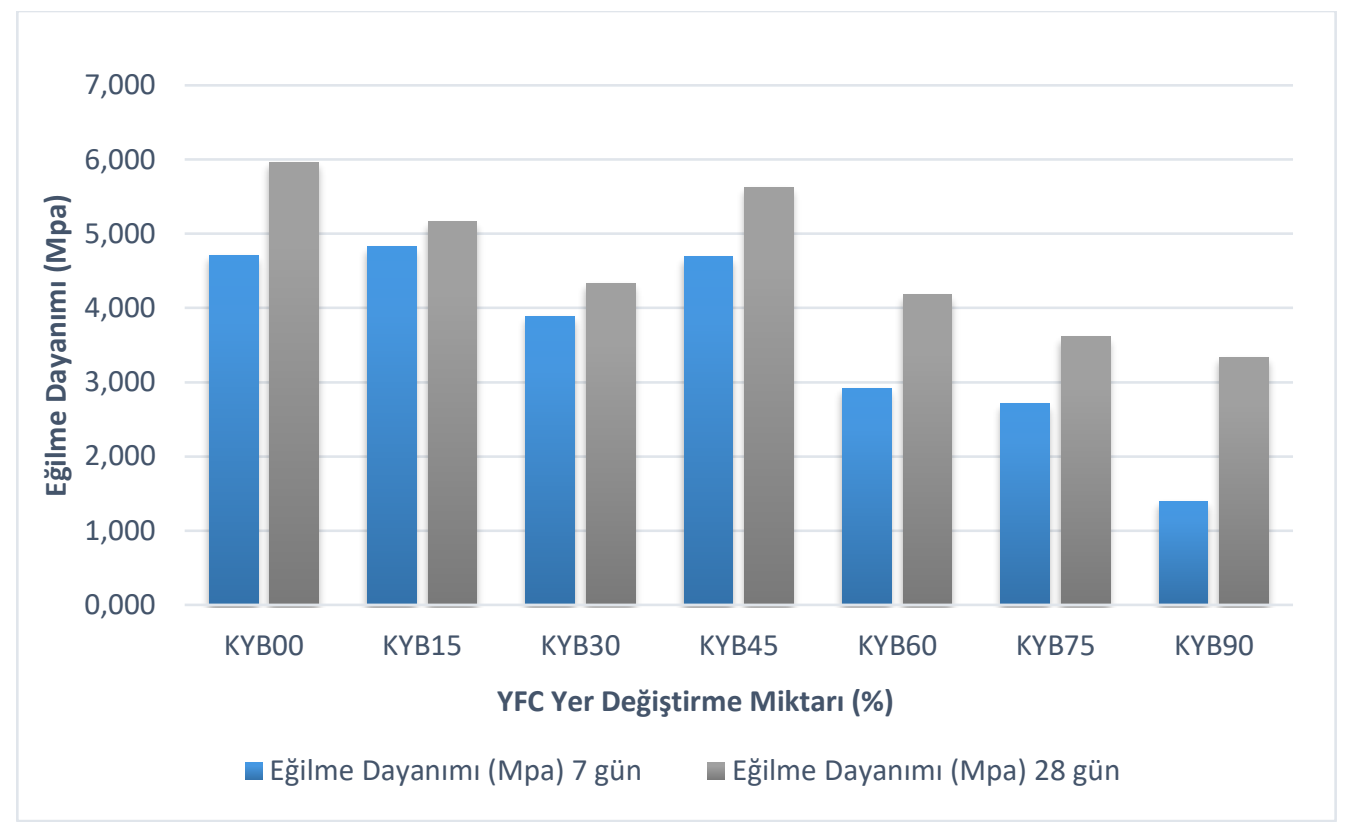

Şekil 6. YFC ile üretilen sertleşmiş betonların 7 ve 28 günlük eğilme dayanımlarının ilişskisi

\subsubsection{Aşınma Deneyi}

710mmx710mmx710mm'lik küp kalıplara dökülen ve gerekli kür koşullarında 28 gün bekletilen numunelere uygulanan aşınma (böhme) deney sonuçları aşağıdaki formülle hesaplanmıştır.

$\Delta \mathrm{V}: 16$ çevrimden sonra hacim kaybı, $\mathrm{cm} 3$

$\Delta \mathrm{m}: 16$ çevrimden sonra kütle kaybı, g

$\rho R$ : Numunenin yoğunluğu, gr/cm3 'dir [17].

Hesaplanan değerler Tablo 14 te verilmiştir. 
Tablo 14. Üretilen betonların 28 günlük aşınma değerleri

\begin{tabular}{cccccccc}
\hline Beton Kodu & KYB00 & KYB15 & KYB30 & KYB45 & KYB60 & KYB75 & KYB90 \\
\hline Aşınma Değerleri & 10,83 & 10,11 & 9,75 & 10,4 & 10,18 & 12,88 & 13,21 \\
\hline Max. Aşınma Değeri & \multicolumn{7}{c}{$18 \mathrm{~cm} 3 / 50 \mathrm{~cm} 2$} \\
\hline
\end{tabular}

Tablo 14 'te görüldüğü gibi en az aşınma miktarı KYB30 numunesindedir. KYB30 numunesi dışındaki numunelerde YFC ikamesi arttıkça aşınma miktarlarının da arttığı görülmüştür. Bütün aşınma değerlerinin TS2824 EN 1338'de öngörülen değerin altında kaldığı görülmüştür[17].

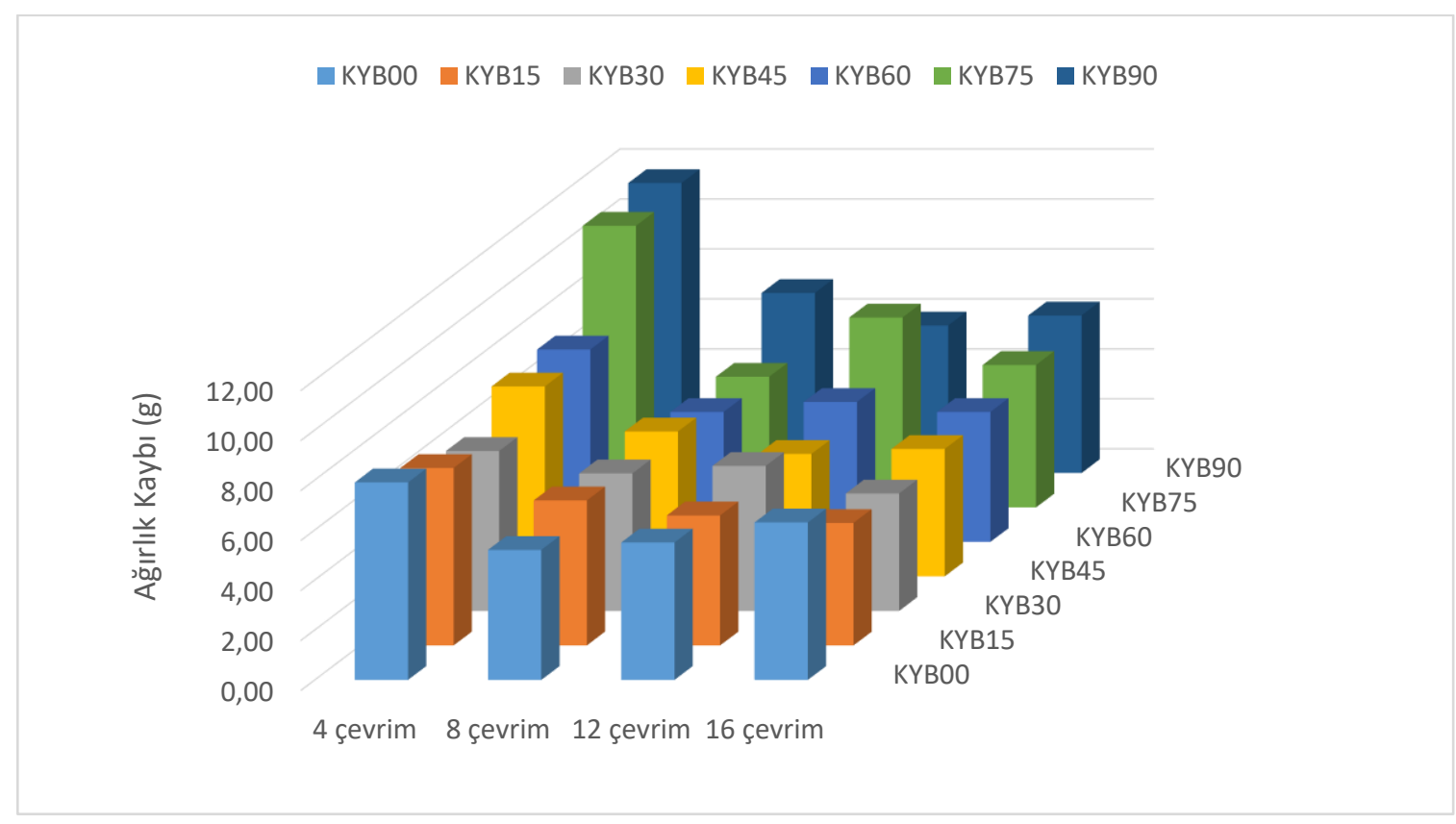

Şekil 7. Aşınma (böhme) deneyi sonucu ağırlık kaybı (g)

Şekil 7 'de de açık şekilde ifade edildiği gibi en fazla aşınma miktarına sahip numune KYB90 numunesidir. Ancak KYB15, KYB30, KYB45 ve KYB60 numunelerinin başlangıca göre aşınma kayıpları kontrol numunesi ile yakındır.

\section{SONUÇLAR}

- HA ve s/b oranı sabit tutularak elde edilen numunelerde yapılan yayılma deney sonuçlarına göre YFC içeren betonların yayılma değerleri arasında anlamlı bir ilişki olmadığı görülmüştür. Ancak bütün sonuçlar EFNARC 'ta (2005) istenilen değerleri sağlamaktadır[12]. En fazla yayılma YFC miktarı en fazla olandadır. Yayılma çaplarının değişkenlik göstermesine rağmen T50 sürelerinde YFC miktarına bağlı olarak artış gözlenmiştir. Sonuç olarak YFC miktarının yayılma süresini uzattığı görülmüştür. 
-YFC miktarı arttıkça betonların birim ağırlıkları ve içerdikleri hava miktarları azalmıştır. YFC miktarının betonun boşluk oranını olumlu etkilediği görülmüştür.

-Elde edilen basınç dayanım değerlerine göre 7 günlük en yüksek dayanım '44,15 Mpa' ile kontrol betonuna aittir. YFC miktarı arttıkça 7 günlük basınç dayanımı düşmüştür. 28 günlük basınç dayanım sonuçlarında ise YFC miktarı en az olan YFC15 betonunun basınç dayanımı '45,36 Mpa' ile en yüksek olduğu görülmüştür. Ancak ileri dayanım kazanmalarının kontrol betonuna göre fazla olduğu da Tablo 11'de gösterilmiştir.

-7 ve 28 günlük en yüksek yarmada çekme dayanımları kontrol betonunda gözlenmiştir. YFC miktarı arttıkça çekme dayanımlarının da ileri dayanım kazanmaları artmıştır.

-Eğilme dayanımları için YFC içeren betonlar arasında en yüksek dayanım KYB45 betonundadır. KYB45 betonundan sonra YFC miktarı arttıkça dayanım azalmıştır.

-16 çevrim sonrasında hesapladığımız aşınma deney sonuçları TS2824 EN 1338'de öngörülen değere göre uygundur[17]. KYB15, KYB30, KYB45 ve KYB60 numunelerinin aşınma miktarlarının kontrol betonunun aşınma miktarına yakın olduğu görülmüştür.

-Bu durumda basınç, yarmada çekme ve eğilme dayanımlarını birlikte değerlendirirsek YFC ile çimentonun \%60'a kadar yer değiştirmesinde istenilen değerlere yakın sonuçlar verdiği, \%60 yer değiştirmede ise uzun süreli dayanım değerlerinin olumlu sonuçlar verdiği fakat YFC \%60 'tan fazla ikame edildiğinde ise istenilen sonuçlara ulaşılamadığı görülmüştür. Ancak aşınma değerlerinden çıkardığımız sonuçlara göre taşıma kapasitesi düşük olarak tasarlanan yol betonlarında, yüzey kaplama betonlarında ve bazı zemin betonlarında yüksek oranlarda YFC kullanımı önerilebilir.

-Böylece yüksek oranda YFC 'nin çimento yerine kullanılmasıyla hem maliyet düşürülmüş olur hem de sürdürülebilir çevreye katkı sağlanmış olur.

\section{KAYNAKLAR}

[1]. İlker Bekir Topçu, Turhan Bilir, Hasan Baylavlı 'Kendiliğinden Yerleşen Betonun Özellikleri’ Eskişehir Osmangazi Üniversitesi Müh. Mim. Fak. Dergisi C.XXI, S.1, 2008

[2] www.insapedia.com/kendiliginden-yerlesen-beton-nedir-kyb-nerelerde-kullanilir/

[3] Hakan Gürdal Akçansa Çimento San. Ve Tic. A.Ş. İstanbul Ziya Yüceer Akçansa Çimento San. Ve Tic. A. Ş. 'Türkiye ve Dünyada Kendiliğinden Yerleşen Beton Uygulamaları' İstanbul

[4] Brouwers, H.J.H., Radix, H.J., 'Self-Compacting Concrete: Theoretical and experimental study', Cement and Concrete Research, 35, 2,2116-2136, 2005.

[5] Levent Eroğlu, Mustafa Şahmaran, İ. Özgür Yaman, Mustafa Tokyay 'Karışım Parametrelerini Kendiliğinden Yerleşen Betonun Taze Özellikleri Üzerindeki Etkilerinin Belirlenmesi' Orta Doğu Teknik Üniversitesi, İnşaat Mühendisliği Bölümü Ankara, Türkiye 
[6]. Bouzoubaa, N., Laclemi, M. 'Self-Compacting Concrete Incorporating High Volumes of Class F Fly Ash Preliminary Results, Cement Concrete Research ’ Vol. 31 No. 3, 413-420, 2001.

[7] Şahmaran, Yaman İ. Ö., Tokyay M., 'Development of High Volume LowLime and HighLime Fly Ash Self Consolidating Concrete', Magazine of Concrete Research,

[8] Yasin Engin 'Yükssek Fırın Cürufu ve Yüksek Fırın Cüruflu Çimento"' www.betonvecimento.com, 2015

[9] M.Emiroğlu, Y. Koçak 'Yüksek Fırın Cürufunun Betonun Fiziksel ve Mekanik Özelliklerine Etkisi'” Düzce Üniversitesi, 2011

[10] Hasbi Yaprak ${ }^{1}$,Osman Şimşek ${ }^{2}$, H. Yılmaz Aruntaş ${ }^{3}$ Bölümü 'Uçucu Kül ve Yüksek Fırın Cürufunun Süper Akışkanlaştırıcı Katkılı Beton Özelliklerine Etkisi’ Ankara Ü. Kastamonu Meslek Yüksek Okulu, Kastamonu ${ }^{1}$, Gazi Ü. Teknik Eğitim Fakültesi Yap1 Eğitimi $^{2-3}$, Ankara

[11] Nalan Kalkan', H. Yılmaz Aruntaş², Engin Demir ${ }^{3}$ 'Yüksek Fırın Cürufu ve Süper Akışkanlaştırıcının Kendiliğinden Yerleşen Beton Özelliklerine Etkisi’ Hacettepe Üniversitesi, Polatlı Teknik Bilimler Meslek Yüksekokulu İnşaat Teknolojisi Programı ${ }^{1}$, Gazi Üniversitesi Teknoloji Fakültesi İnşaat Mühendisliği Bölümü ${ }^{2}$, Sigma Beton Lab. Hiz. ve Tic.Ltd.Şti ${ }^{3}$, Ankara

[12] EFNARC (European Federation of National Trade Associations), Specification and Guidelines for Self-Compacting Concrete, 2005.

[13] TS EN 932-1, (1997) 'Agregaların genel özellikleri için deneyler-Kısım 1 numune alma metotları', Türk Standartları Enstitüsü

[14] TS EN 933-1, (2015) 'Agregaların Geometrik Özellikleri İçin Deneyler Bölüm 1: Tane Büyüklüğü Dağılımı Tayini - Eleme Metodu’, Türk Standartları Enstitüsü

[15] TS EN 15167-1, (2006) Öğütülmüş yüksek firın cürufu - Beton, harç ve şerbette kullanım için - Bölüm 1: Tarifler, özellikler ve uygunluk kriterleri, Türk Standartları Enstitüsü

[16] TS 802, (2009) 'Beton karışım tasarımı hesap esasları', Türk Standartları Enstitüsü

[17] TS2824 EN 1338, (2005)‘Zemin döşemesi için beton kaplama blokları - Gerekli şartlar ve deney metotları', Türk Standartları Enstitüsü

[18] TS 699, (2009)‘Tabii yapı taşları-Muayene ve deney metotları’, Türk Standartları Enstitüsü 